\title{
Critical Thinking and Debiasing: Experimentation in an Academic Writing Course
}

\section{Guy Smith \\ International Christian University \\ John Peloghitis \\ International Christian University}

\section{Reference Data:}

Smith, G., \& Peloghitis, J. (2020). Critical thinking and debiasing: Experimentation in an academic writing course. In P. Clements, A. Krause, \& R. Gentry (Eds.), Teacher efficacy, learner agency.

Tokyo: JALT. https://doi.org/10.37546/JALTPCP2019-51

In the last two decades, interest in cognitive biases has rapidly grown across various fields of study. The research so far has shown that cognitive biases have significant and sometimes adverse effects on decision making. Thus, it is increasingly being argued that classroom teaching of critical thinking needs to include instruction and training that help students understand cognitive biases and reduce their negative effects on judgment and decision making. Teaching students to be aware of biases and to develop and maintain strategies to reduce their influence is known as debiasing. The purpose of this paper is to provide an overview of cognitive biases and a framework for debiasing proposed by Wilson and Brekke (1994). Two approaches, modifying the person and modifying the environment, are discussed to help teachers introduce activities and strategies to mitigate biases.

認知バイアスへの関心は、この20年で様々な領域で急激に高まってきた。認知バイアスが、意思決定に対し有意な影響、 時には逆効果を及ぼすことが、これまでの研究で明らかになった。そのため、教室で批判的思考を教える場合も、学生の認知 バイアスへの理解に役立ち、認知バイアスが判断力や意思決定に対して及ばす、時には有害な影響を弱める思考法を教える 練習ないし訓練を組み込む必要があるのではないだろうか。学生がバイアスを認識し、その影響を払拭ないし弱める思考法 を身につけてそれを維持するよう教えることは、デバイアスという名称で知られている。本稿では、認知バイアスとWilson and Brekke (1994) が提案するデバイアスのプロセスを概観する。教師がバイアスを和らげるための活動と戦略を紹介できるよう に、人間を修正し、環境を修正するという二つの取り組みについても検討する。 esearch and interest in cognitive heuristics (shortcuts in thinking) and cognitive biases (thinking predispositions or tendencies) has grown rapidly in the past 10 to 15 years. What is known about cognitive biases today owes much to work drawn from behavioral economics, social psychology, decision making, and error studies. Recently, the cognitive bias discussion has found a much wider audience with the publication of popular science books such as Nudge by Richard Thaler and Cass Sunstein (2008), Predictably Irrational by Dan Ariely (2009), Daniel Kahneman's Thinking, Fast and Slow (2011), and Robert Cialdini's Pre-suasion (2016). These books provided the general public with a fascinating and, in some ways, unsettling look into how we think. The research demonstrated that judgments and decisions often emerge from taking thinking shortcuts, relying on our intuitions and feelings, and attending to certain stimuli while ignoring others. Some of the biases that emerge from these cognitive processes include confirmation bias (to look for or interpret information that confirms a previous belief), ingroup bias (a tendency to favor members of your in-groups) and the aptly named ostrich effect (the tendency to ignore negative situations).

\section{Difficulty Correcting for Cognitive Biases}

For the most part, our cognitive processes work efficiently in getting us through daily life. We act and behave in ways that efficiently solve the problems and complexities that we typically encounter (Bloom, 2016). However, our brains have a limit to the amount of information processing that can be done in a short period of time (Haselton, Nettle, \& Murray, 2015), and as a result, the brain often favors using mental shortcuts and general rules in an attempt to make the decisions and judgments simpler (Tversky \& Kahneman, 1974). These shortcuts and general rules allow us to make decisions quickly, are energy efficient, free up cognitive processing, and are quite effective. In our evolutionary history, most of which has been as hunter-gatherers, the speed and rightness of decision-making, often on the availability of little evidence, has frequently made the difference between survival or death (Haselton et al., 2009). However, one by-product of this fast, intuitive 
thinking is that because we use these predisposed patterns of thinking, we are prone to errors, such as cognitive blind spots, over-generalizations, and stereotyping. These unequal thinking patterns, or cognitive biases, are one way that thinking can give rise to systematic and predictable error tendencies (Ariely, 2009).

Kahneman (2011) argued that there are two main ways of thinking, derived to serve different purposes. One way is a fast, automatic, and intuitive style (referred to as System 1), while the other is slower, reflective, and more rational (System 2). Cognitive biases can emerge from either style of thinking. While the dual-processing System 1 and 2 approach has been criticized as being too simplistic to express the whole complexity of cognitive processes (Melnikoff \& Bargh, 2018), it has been a widely accepted and useful model for understanding how many cognitive biases emerge as the consequence of intuitive thinking.

Croskerry, Singhal, and Mamede (2013) provided a summary of the origins of such intuitive thought processes as being from four processes: (a) hard-wired instincts and intuitions, (b) our emotions, (c) attitudes and thought processes rooted in our social and cultural learning contexts, and (d) our implicit learning of societal norms or expectations. The intuitive origin of some biases means that it is difficult, if not impossible, for individuals to become consciously aware of them and correct them (Beaulac \& Kenyon, 2018). Cognitive bias is also formed by blending intuitive and intentional processes and moving back and forth between the two (Melnikoff \& Bargh, 2018). However, correction can be done. Some research has shown that when speaking another language, the slowed cognitive processing leads to a reduction of cognitive biases (e.g., Kesar, Hayakawa \& An, 2012).

\section{What Is Debiasing?}

Cognitive biases tend to be the result of fast, intuitive thinking. As this kind of thinking tends to be at the level of the unconscious, the very nature of the thinking raises serious challenges to the question of how biases can be reduced, mitigated, or removed completely. Debiasing refers to the attempt to address this question.

Wilson and Brekke (1994) provided a useful framework for understanding how debiasing works in educational contexts (see Figure 1). The model describes the process of debiasing in seven stages. For a learner to make effective decisions, they must move through each stage (indicated by the arrows in Figure 1) by developing an awareness of their biases and applying strategies to mitigate them. Debiasing failure occurs when individuals fail to meet the objectives required at any stage of the process. The framework explains that a cognitive bias begins when an unwanted mental process is triggered. To mitigate the unwanted bias, one must be able to detect it. Detection is challenging because it is an unconscious process by which we form judgments with no signs that a bias is occurring (Nisbett \& Wilson, 1977). If a learner detects a bias in their thinking, they then must be motivated to correct it. They must be aware of the direction and magnitude of their error and have sufficient control over their judgments to amend it. For example, in the case of someone negatively evaluating a person based on gender, the magnitude and direction would entail an awareness of the extent of the negative perception and how strongly this perception shapes the evaluation. Lastly, learners must understand debiasing strategies and techniques and be able to select the appropriate strategy to mitigate the bias successfully. If all of these conditions are satisfied, a bias can be effectively mitigated, allowing for a better decision to be made. Although newer frameworks have been proposed (see Bhandari \& Hassanein, 2012; Croskerry, Singhal, \& Mamede, 2013), they addressed specialized areas, such as clinical care and investment strategies, that offer little guidance in understanding how debiasing can take place in an academic writing context.

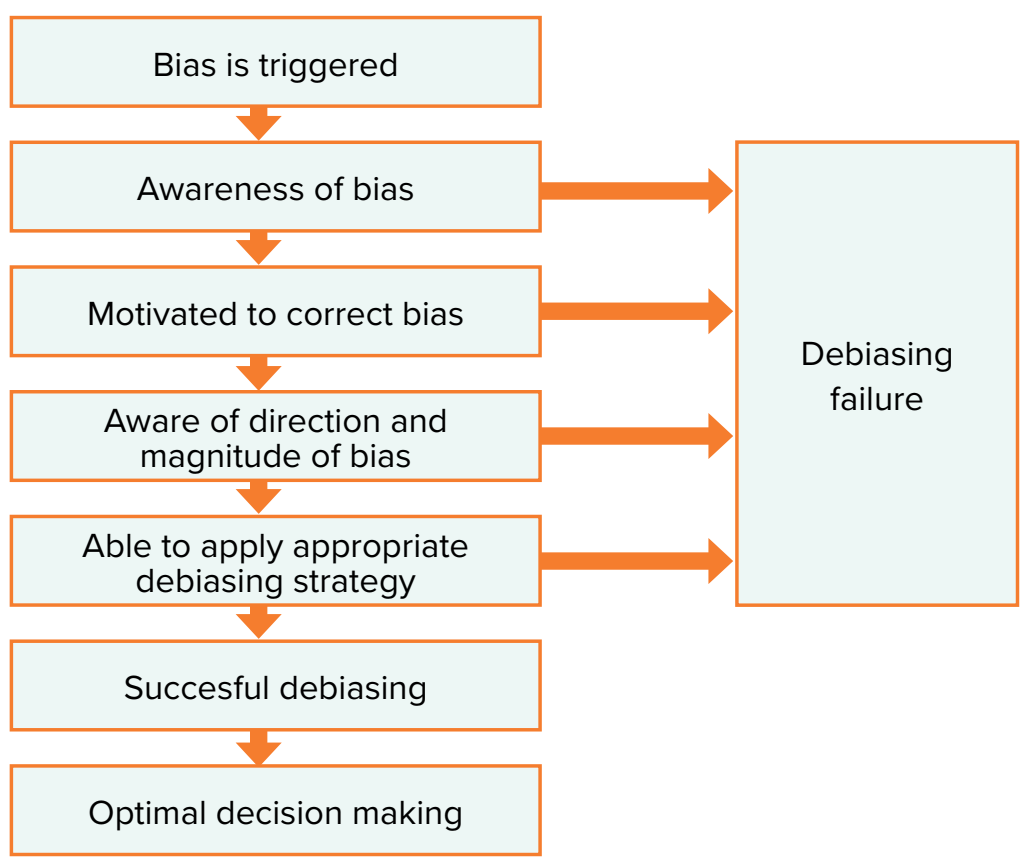

Figure 1. Wilson and Brekke's model of mental contamination (1994). 


\section{Can Debiasing Be Taught?}

Some scholars have claimed that teaching critical thinking to help students develop debiasing techniques is ineffective because cognitive biases are deeply rooted and immune to critical thinking instruction (e.g., Mercier \& Sperber, 2011; Willingham, 2007; Wilson, Centerbar, \& Brekke, 2002). In contrast, supporters of critical thinking approaches to teach debiasing have stressed that the lack of empirical evidence is due to the rather narrow definition attributed to critical thinking. Kenyon and Beaulac (2014) have been skeptical of educational practices that focused on explicit teaching of strategies to remove common cognitive biases. They consider this to be the intuitive approach (IA) to teaching debiasing and question its efficacy as a method to teaching debiasing. They do, however, point towards teaching biases explicitly as a first step and suggest training teachers to apply situational constraints to debias otherwise distorted judgments. Despite the negative opinions from previous research, we argue that teachers can provide activities that raise student awareness of bias in their thinking. In the next section we provide some suggestions based on trial and error to carry out a critical thinking approach to student debiasing in an academic reading and writing course. We implemented exercises to raise student awareness and help them choose strategies to mitigate biased reasoning utilizing Wilson and Brekke's (1994) model as a framework.

\section{Triggering a Bias}

Teachers can begin by triggering a bias in their students. This enables learners to understand that they are susceptible to committing biased reasoning. An effective start is to introduce the anchoring heuristic, which is a priming effect whereby initial exposure to an anchor, such as a number, serves as a reference point and influences subsequent judgments. People tend to adjust an estimate or value based on the reference point or anchor presented regardless of whether the anchor is reasonable or not. Teachers ask a simple question that includes different reference points presented to two groups of students. Then each group is required to give a more specific estimate. For example,

Group 1

a) Is the length of the Mississippi River greater or less than 3000 miles? b) What is the length of the Mississippi River?

\section{Group 2}

a) Is the length of the Mississippi River greater or less than 300 miles?

b) What is the length of the Mississippi River?

Students are unlikely to know the length of the Mississippi River in miles, so the numbers 300 and 3000 are suitable anchors that led to faulty estimates based on the information presented. Group 1 (3000 miles reference point) had a medium estimate of 1250 miles; whereas, Group 2 (300 miles) had a medium estimate of 455 miles. These results provide evidence of an anchoring effect in which students' judgments were influenced by an uninformative number (Kahneman, 2011)

The confirmation bias exercise is another effective activity to help learners trigger a bias. For this exercise, students have to discover a "rule" that is only known to the teacher. Students are given the numbers 2-4-6 and told that this series of numbers fits the rule. They write three numbers on the handout (see Appendix A), and the teacher tells them whether the three numbers fit the rule or not. Students have an unlimited number of attempts to decipher the rule until they feel confident that they know the rule. Most students quickly assume that the rule is a series of even numbers, which increase by multiples of two. The confirmation bias is shown when students denote a strong level of confidence in their answers after verifying only two or three series of numbers (e.g., 4-8-16, 6-12-18) with their teacher. Few students will attempt to falsify their hypothesis by providing a series of numbers that test a different rule, such as a series of odd numbers or numbers that decrease. The rule is simply "a sequence of ascending numbers." Students are often shocked after learning how quickly and confidently they confirmed an initial belief without checking other possibilities. Students then realize how confirmation bias can affect other decisions, such as looking for sources or choosing argumentative essay topics.

After students realize that they are susceptible to cognitive biases, teachers can help them foster an awareness of other common cognitive biases. Teachers can assign students one or two biases to research and present in small groups. Students are encouraged to incorporate exercises to trigger biases in their groups then explain them in more detail using examples. There are plenty of resources on the Internet as well as in the books mentioned earlier that offer clear explanations and examples for students to start exploring different cognitive biases. One of the biases assigned in our course was the base rate fallacy (people place more weight on new information and unconsciously 
fail to consider the original data or base rate to make a judgment). Students usually find intriguing examples to illustrate the bias such as the scenario in Appendix B, and these exercises are distributed to their group members. Students answer the exercises individually and then discuss their choices in groups. Other popular cognitive biases to assign students to research are the affect heuristic (using emotions such as fear, pleasure, or fear to solve problems quickly), the availability heuristic (relying on immediate examples that come to a given person's mind when evaluating a specific topic, concept, or decision), and the hindsight bias (the tendency for people to perceive events that have already occurred as having been more predictable than they actually were before the events took place).

\section{Building Awareness of Cognitive Biases}

For the next stage of the mental contamination model, teachers give students scenarios to help them build awareness of the consequences of biased thinking. One scenario has students doing peer assessment on a short essay. Another scenario has groups of students choosing the most qualified editor to run a local newspaper. Exercises that examine desirable qualifications, stereotypes generated from the candidate's appearance, and personal beliefs about newspaper companies are discussed in groups or as a class so students become aware that cognitive biases can occur in many situations. The aim of these scenarios is for students to realize how knowledge of personal information or ambiguous evaluation criteria can lead to subjective decisions when assessing a piece of writing or hiring a person for a job. These two scenarios challenge students to begin thinking about how much biases can shape decisions and slant judgments.

\section{Removing Biases}

From our experience, the most challenging task for teachers is having students apply debiasing strategies and techniques because it involves training them to slow down their mental processes, which is the next stage of the mental contamination model. Debiasing approaches largely fall under two categories: modifying the person and modifying the environment.

\section{Modifying the Person}

The first debiasing approach, modifying the person, entails teaching corrective strategies in which learners can apply a strategy to avoid or mitigate a cognitive bias. The type of instruction depends on the type of situation and the cognitive bias being mitigated; for example, knowledge of probability and statistics can help mitigate the conjunction bias (the faulty assumption that specific conditions are more probable than a single general one). Introducing decision devices is effective in reducing biased judgments as it transforms the decision environment.

One way to help students detect and mitigate biases is to teach them how to analytically reconstruct arguments and data (van Eemeren \& Grootendorst, 2004). This approach can reveal various biases such as the belief bias, which is the tendency to accept one's conclusions as true because they are believable instead of being logically valid (Leighton \& Sternberg, 2004). Writers are often unaware of their assumptions and the extent to which these can bear on their reasoning. The effort to analyze the components of an argument can render such commitments explicit, thereby allowing a writer to become aware of their biased reasoning. The following argument has been used in our class to examine deductive thinking.

The United Nations is useless and should be shut down. The U.N. has been unable to prevent conflict and war for the last 20 years around the world, even though it has been supplied with peace-keeping forces at great expense to member nations.

This argument is flawed because its premises contain assumptions. For instance, it presents a simplified perspective on the responsibilities of the U.N. by judging effectiveness solely on its ability to stop war. In addition, the writer has not considered that the number of conflicts may be larger if not for the efforts by the United Nations. Having students identify premises and conclusions are helpful activities in the early stages of the writing process and can be beneficial for framing sound arguments.

Debiasing through instruction education is grounded in the belief that teaching logic, and in some cases, probability and statistics can facilitate more objectivity and reduce biased reasoning. Students who have a strong foundation in logic, statistics, and argumentation might be more likely to discover their own biases. An activity that demonstrates this claim is Tversky and Kahneman's (1983) well-known "Linda problem," which illustrates the conjunction bias. In our course, we followed the original version by presenting a description of Linda, a fictitious person, as a 31-year-old activist deeply concerned with issues of discrimination and social justice. Then we asked the participants which of the following possibilities is more likely: (a) Linda is a bank teller, or (b) Linda is a bank teller and is active in the feminist movement? A majority of our students chose the second option, thereby transgressing an elementary rule of probabilities: The conjunction of two conditions cannot be more probable than one of the events alone. Tversky and Kahneman (1983) asked this question of graduate students who had taken a statistics course. Only $36 \%$ committed the fallacy as opposed to 85 to 
$90 \%$ of college students who had not taken a statistics course. The results indicated that at least in certain instances, the development of statistical knowledge and deductive skills can work as a safeguard against systematic errors of intuitive reasoning. We also presented basic statistics and probability exercises in our course to reduce these types of biases. The results were similar to those seen in Tversky and Kahneman's research.

Another activity is to have students look at issues from different perspectives. Having students identify stakeholders who have a vested interest in an issue (e.g.,. hosting the Olympics) can help them develop multiple perspectives. This type of exercise helps prevent narrow thinking, which is a common bias when we fail to consider enough possible future outcomes when making our decisions. When writing an argumentative essay in an academic writing course, learners can be required to use prewriting routines to collect different perspectives from various sources before choosing a position. In-class discussion activities in which students argue from an opposing perspective can also be used to force students to consider different viewpoints more carefully. Assignments that incorporate counter arguments and refutations can be invaluable to show that a writer has undertaken considerable analysis and reflection (applying System 2 thinking) in researching the topic.

Checklists encourage learners to use systematic approaches to complete writing tasks. They can also be used to minimize errors and biases, such as the bias blind spot where people think they are less susceptible to biases than others. According to Hales and Pronovost (2006), checklists can ensure that specific tasks have been completed by referring to a list of criteria. At each stage of the drafting process, learners can be given a checklist of tasks to be completed before submitting an essay. The advantages of checklists are most advantageous in reviewing written work at the final stage when, in most cases, teachers are expecting a polished piece of writing. Eventually, students should be encouraged to design their own checklists to use in subsequent assignments.

\section{Modifying the Environment}

The second approach focuses on modifying the environment by designing one's decisionmaking environment in a way that prevents or offsets predictable biases (Arnott,

2006; Kahneman, Lovallo \& Sibony, 2011; Klayman \& Brown, 1993). One approach to debiasing is to change the decision-making environment by eliminating the incidence of bias before it occurs. For example, in anticipating a common potential error, someone designing a decision-making environment (a "choice architect") can structure that environment to "nudge" choices in wise directions (Thaler \& Sunstein, 2008). Nudges are designs that use psychological principles to influence behavior for the better by pushing people in a specific direction. Nudges do not restrict choice and help people avoid making poor decisions (Ly, Mazar, Zhao \& Soman, 2013; Thaler \& Sunstein, 2008) A manager placing bottled water near the check-out counters instead of soda cans to encourage people to buy less soda can qualify as a nudge, but completely eliminating soda cans from the store does not.

Without realizing it, most of us use nudges in our everyday life, from hiding money somewhere in our home or wallet in case of an emergency to setting our alarm clock away from the bed to force us to get up to turn it off. A good activity to begin with is to draw on student experiences using nudges and let them discuss why they are used. Students have often mentioned digital apps that help them save money, exercise, and limit time on the Internet. Academic writing teachers can also incorporate nudges into the writing process to help learners make wise decisions, for instance, requiring students to use an extension that examines spelling and grammar (Grammarly is one popular option that offers this feature). In addition, notifications can be added when students add or resolve comments during peer feedback. These notifications inform peers that changes have been made to a document they shared.

Another nudge a teacher can use is establishing the default option when doing an activity. For example, in an academic writing course, when offering students several choices for drafting their essays, a nudge could be to make the preferred option (or default) be working on an e-portfolio that has links embedded to exercises and online tools for editing. According to the research on the use of defaults, students are unlikely to opt out of using these embedded procedures (Chapman et al., 2010; McKenzie, Liersch, \& Finkelstein, 2006). In this way, students are implicitly choosing the recommended course of action. Using a template for students to input evidence to support their claims in an essay is another area where defaults can influence what is required to build a sound argument. For example, a template can direct students to specify their premises and conclusion. Modifying the environment begins with teacher-initiated nudges, but eventually the goal should be to develop a capacity in students to modify their own environment.

Nudges can also be utilized to facilitate reflection. Significant decision biases often derive from an under-reliance on the slower and more rational System 2 (or an overreliance on the quick, intuitive System 1) and can thus be reduced by nudging learners to deeply reflect on their decisions. Such nudges require people to devote more time and attention to a decision, often by more explicitly elaborating on their objectives and plans.

Activities that can slow down thinking are forced breaks, partitioning work, planning prompts, and checklists. Forced breaks are natural breaks that are imposed on choice 
processes, and these breaks lead to slower decisions and deeper processing. Partitioning work, such as allotting separate times to accomplish a series of tasks, can help students to learn to regulate their learning. Planning prompts have learners formulate a feasible design to complete a desired task. They have also been successful in nudging students to follow through on their intentions. An example of a planning prompt is allowing students to individually determine the submission dates for their essay drafts. Shortly after deciding on a plan, students are encouraged to articulate it to other classmates to induce reflection. When an individual is prompted to decide on the when, where, and how of an intended action (i.e., deadlines for an essay), the plan forms a commitment that is psychologically difficult to break (Gollwitzer \& Sheeran, 2006). Lastly, checklists slow down thinking by having students systematically examine specific features of their writing before submission or during revision. Checklists, for example, can ask learners to review their essays for formatting issues or citation errors.

\section{Conclusion}

The main objectives of this paper are to explain the role cognitive biases have in hindering the decision-making process and introduce the process of debiasing and its importance in critical thinking instruction and the teaching of academic writing. We contend that to apply debiasing strategies and nudges effectively, moving beyond the intuitive approach and instructing students to build a repertoire of strategies is essential. Debiasing is a complex multifaceted process that needs repeated practice and time for reflection. Critical thinking education in academic writing courses should include extensive practical guidance on how to apply debiasing strategies and structure one's environment to create optimal decisions. By following a systematic model such as that of Wilson and Brekke (1994) and integrating activities that foster an awareness of cognitive biases, teachers can provide their students with more meaningful instruction to help them acquire the skills to think and write in a more rational manner.

\section{Bio Data}

Guy Smith teaches at International Christian University in Tokyo in the English for Liberal Arts program. His teaching and research interests are in self-determination theory, student well-being, and critical thinking. Correspondence related to this article should be directed to <guys@icu.ac.jp>

John Peloghitis currently resides in western Tokyo and is presently teaching as an instructor in the English Liberal Arts Program at International Christian University in
Japan. He teaches academic reading and writing, debate, and research writing. He is interested in second language writing, metacognitive strategies, syllabus design, and critical thinking.

\section{References}

Ariely, D. (2009). Predictably irrational. London, England: HarperCollins.

Arnott, D. (2006). Cognitive biases and decision support systems development: A design science approach. Information Systems Journal, 16(1), 55-78. https://doi.org/10.1111/j.13652575.2006.00208.x

Beaulac, G., \& Kenyon, T. (2018). The scope of debiasing in the classroom. Topoi, 37(1), 93-102. https://doi.org/10.1007/s11245-016-9398-8

Bhandari, G., \& Hassanein, K. (2012). An agent-based debiasing framework for investment decision-support systems. Behaviour \& IT, 31, 495-507. https://doi.org/10.1080/014492 9X.2010.499477

Bloom, P. (2016). Against empathy: The case for rational compassion. New York, NY: HarperCollins.

Chapman, G. B., Li, M., Colby, H., \& Yoon, H. (2010). Opting in vs opting out of influenza vaccination. JAMA, 304(1), 43-44. https://doi.org/10.1001/jama.2010.892

Cialdini, R. (2016). Pre-suasion: A revolutionary way to influence and persuade. New York, NY: Simon and Schuster.

Croskerry, P., Singhal, G., \& Mamede, S. (2013). Cognitive debiasing 1: Origins of bias and theory of debiasing. BMJ Quality \& Safety, 22, ii58-ii64. https://doi.org/10.1136/bmjqs-2012-001712

Gollwitzer, P. M., \& Sheeran, P. (2006). Implementation intentions and goal achievement: A meta-analysis of effects and processes. Advances in Experimental Social Psychology, 38(1), 69-119. https://doi.org/10.1016/S0065-2601(06)38002-1

Hales, B. M., \& Pronovost, P. J. (2006). The checklist: A tool for error management and performance improvement. Journal of Critical Care, 21(3), 231-235. https://doi.org/10.1016/j.jcrc.2006.06.002

Haselton, M. G., Bryant, G. A., Wilke, A., Frederick, D. A., Galperin, A., Frankenhuis, W. E., \& Moore, T. (2009). Adaptive rationality: An evolutionary perspective on cognitive bias. Social Cognition, 27(5), 733-763. https://doi.org/10.1521/soco.2009.27.5.733

Haselton, M. G., Nettle, D., \& Murray, D. R. (2015). The evolution of cognitive bias. In D. M. Buss (Ed.), The handbook of evolutionary psychology (Vol. 2, 968-987).. https://doi. org/10.1002/9781119125563.evpsych241

Kahneman, D. (2011). Thinking, fast and slow. New York, NY: Farrar, Straus, and Giroux.

Kahneman, D., Lovallo, D., \& Sibony, O. (2011). Before you make that big decision... Harvard Business Review, 89(6). Retrieved from https://www.researchgate.net/publication/51453002_ Before_you_make_that_big_decision 
Kenyon, T., \& Beaulac, G. (2014). Critical thinking education and debiasing. Informal Logic, 34(4), 341-363. https://doi.org/10.22329/il.v34i4.4203

Keysar, B., Hayakawa, S. L., \& An, S. G. (2012). The foreign-language effect: Thinking in a foreign tongue reduces decision biases. Psychological Science, 23(6), 661-668. https://doi. org/10.1177/0956797611432178

Klayman, J., \& Brown, K. (1993). Debias the environment instead of the judge: An alternative approach to reducing error in diagnostic (and other) judgment. Cognition, 49(1), 97-122. https:// doi.org/10.1016/0010-0277(93)90037-V

Leighton, J. P., \& Sternberg, R. J. (2004). The nature of reasoning. New York, NY: Cambridge University Press.

Ly, K., Mazar, N., Zhao, M., \& Soman, D. (2013). A practitioner's guide to nudging. Rotman School of Management Working Paper No. 2609347. Retrieved from https://ssrn.com/abstract=2609347

McKenzie, C. R. M., Liersch, M. J., \& Finkelstein, S. R. (2006). Recommendations implicit in policy defaults. Psychological Science, 17(5), 414-420. https://doi.org/10.1111/j.1467-9280.2006.01721.x

Mercier, H. \& Sperber, D. (2010). Why do humans reason? Arguments for an argumentative theory. Behavioral and Brain Sciences, 34(2), 57-74. https://doi.org/10.1017/S0140525X10000968

Nickerson, R. S. (1998). Confirmation bias: A ubiquitous phenomenon in many guises. Review of General Psychology, 2(2), 175-220. https://doi.org/10.1037/1089-2680.2.2.175

Nisbett, R. E., \& Wilson, T. D. (1977). Telling more than we can know: Verbal reports on mental processes. Psychological Review, 84(3), 231-259. https://doi.org/10.1037/0033-295X.84.3.231

Thaler, R. H., \& Sunstein, C. R. (2008). Nudge: Improving decisions about health, wealth, and happiness. New Haven, CN: Yale University Press.

Tversky, A., \& Kahneman, D. (1974). Judgment under uncertainty: Heuristics and biases. Science, (4157). 1124. https://doi.org/10.1126/science.185.4157.1124

Tversky, A., \& Kahneman, D. (1983). Extensional versus intuitive reasoning: The conjunction fallacy in probability judgment. Psychological Review, 90(4), 293-315. https://doi. org/10.1037/0033-295X.90.4.293

van Eemeren, F. H., \& Grootendorst, R. (2004). A systematic theory of argumentation: The pragma dialectical approach. New York, NY: Cambridge University Press.

Willingham, D. T. (2007). Critical thinking: Why is it so hard to teach? American Educator, 31, 8-19. https://doi.org/10.3200/AEPR.109.4.21-32

Wilson, T. D., Centerbar, D. B., \& Brekke, N. (2002). Mental contamination and the debiasing problem. In T. Gilovich, D. Griffin, \& D. Kahneman (Eds.), Heuristics and biases: The psychology of intuitive judgment (pp. 185-200). Cambridge, England: Cambridge University Press.
Wilson, T. D., \& Brekke, N. (1994). Mental contamination and mental correction: Unwanted influences on judgments and evaluations. Psychological Bulletin, 116, 117-142. https://doi.org/ 10.1037/0033-2909.116.1.117

\section{Appendix A}

Confirmation Bias Exercise

\begin{tabular}{|c|c|c|c|c|}
\hline & Number Series & Fits? Yes/No & Proposed Rule & \% Confidence* \\
\hline 1 & $2-4-8$ & Yes & & \\
\hline 2 & & & & \\
\hline 3 & & & & \\
\hline 4 & & & & \\
\hline 5 & & & & \\
\hline 6 & & & & \\
\hline 7 & & & & \\
\hline
\end{tabular}

$* 0 \%=$ no confidence, $100 \%=$ complete confidence 


\section{Appendix B \\ Exercise for Examining Base Rates}

\section{Scenario:}

The local university consisting of 1000 students has started using a computer program that detects plagiarism in student essays. Each year the software checks every student's essay once. The software has a false positive rate of $5 \%$. Every year it mistakes $5 \%$ of original, non-plagiarized essays for plagiarized ones. However, the software never fails to detect a truly plagiarized essay. All essays that are truly plagiarized are detectedcheaters are always caught.

Plagiarism at the university is not very common. On average, one out of a thousand students will commit plagiarism in their essays. Recently, the software detected that an essay handed in by John, a 1st-year university student, has been plagiarized.

What do you think is more likely?

a) John is guilty and has indeed committed plagiarism

b) John is innocent as a result of a false positive.

\section{Answer:}

There is a greater likelihood that John is innocent since it is more likely that John's essay has been falsely determined to be plagiarized $(5 \%)$ rather than the chance that John is guilty (2\%). The percentage is determined by applying Bayes rule which is the probability of $\mathrm{A}$ (the actual plagiarism rate) / probability of $\mathrm{B}$ (the positive test result by the plagiarism detection software). In other words, .001 divided by .05 equals .02 or $2 \%$. Students generally focus on John being the only one found plagiarizing when in fact there would be a group of 50 students ( $5 \%$ of 1000 students). 